\section{A little regulation}

\section{Regulators are beginning cautiously to navigate the uncharted waters of nanotechnology.}

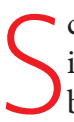
cientists, businesses and politicians are growing increasingly interested in the safety of nanomaterials. Panel after panel has been convened to discuss whether substances engineered on the nanometre scale pose different environmental, health and safety risks from those engineered on larger scales. Report after report has called for greater scrutiny of any possible effects (see Nature 444, 267-269; 2006).

So it should come as no surprise that US regulators have finally agreed on their first ruling concerning nanoparticles. In a decision that came to light last week, the Environmental Protection Agency (EPA) plans to regulate products marketed as antimicrobial because they contain nano-sized particles of silver. In essence, companies will no longer be able to sell things such as odour-eating silver shoe inserts without being able to prove - in a manner yet to be defined - that the particles will not harm the environment.

The ruling stems from a challenge over a Samsung washing machine, which is claimed to release silver ions to sterilize clothes. Environmentalists challenged an EPA decision last year that the washing machine was a 'device' and so did not need to be regulated. (Typically, devices that release pesticides are not regulated, but the pesticides are.) The agency reconsidered and now says the silver nanoparticles can be considered to be a pesticide, and so need to be regulated.

Companies that make and market nanoproducts have yet to see how environmental concerns may affect their business plans (see Nature 443, 137; 2006). But the EPA is, in this case, taking a step in

the right direction. Clearly, many details remain to be worked out; the new ruling, for instance, leaves a significant loophole, as companies will be able to stop marketing their devices as antimicrobial and continue to sell them without regulation. But despite the criticism often hurled at them, regulators (at least in the United States and Europe) have a reasonably good track record of evolving their rules to protect the public interest.

The impact of all this on nanotechnology researchers and businesses will depend on how regulatory agencies cope with the dizzying array of products that will be produced under the wide rubric of 'nanotechnology'. If regulation is to be fair and effective, agencies will have to work closely together. Nanosilver, for instance, falls under the purview of the EPA when the particles could be released into the environment, such as in waste water from a washing machine. But it becomes the responsibility of the Food and Drug Administration for medical applica-

"The Environmental Protection Agency's decision is the first, necessary step along what promises to be a lengthy road."

tions, such as when nano-sized silver particles are used on bandages to kill germs. Regulators from various agencies routinely attend nano-safety seminars and background briefings together; soon we will discover how much they have learned.

The scientific community, for its part, plays an important role in the development of technologies, including nanotechnology. But that doesn't mean it supports every application. Like everyone else, scientists want to see intelligent regulation. They should not interpret the EPA decision as negative: it is the first, necessary step along what promises to be a lengthy road. Regulators cannot begin to work their way through different health and safety risks until the first rules are on the table. Now they are.

\title{
Not the end of an era
}

\section{The Mars squadron loses its commodore.}

T he loss of the Mars Global Surveyor, a NASA spacecraft that has stopped talking to its controllers, is a sad event. It is impossible not to feel a sentimental 'brave little toaster' bond to a spacecraft that served its Earthly masters so faithfully for so long, and revealed so many wonders. And yet one cliché of loss often used in such situations is, on this occasion, happily inappropriate: this is most definitely not the 'end of an era'. Although the Surveyor is gone, almost ten years to the day after it was launched, the era it ushered in - that of the first continuous, if virtual, human presence at another planet - is still in full swing (see page 526).

For most of the 1980s and 1990s there was hardly any news from Mars. Since the Mars Global Surveyor started doing science in 1999 (getting into the correct orbit was a time-consuming procedure), the flow of data has been uninterrupted. Its cunningly designed camera revealed details of the surface never seen before, including fresh-looking gullies that appear to have been cut by water. Its magnetometer picked up the planet's intriguingly patterned magnetic field. Its laser altimeter provided a topographic map far more accurate than anything that had come before. These instruments on their own would have revolutionized our view of the planet.

But they were not on their own. New spectroscopic capabilities were added by Mars Odyssey in 2002 and by the European Space Agency's Mars Express in 2004, which also provided a radar and a new camera. Information from the ground at two sites was provided by NASA's remarkably enduring Mars rovers, Spirit and Opportunity. This summer the heavyweight Mars Reconnaissance Orbiter joined the squadron with perhaps the most impressive instruments to date. The Phoenix lander is due to join them in a couple of years, and a more capable rover, Mars Science Laboratory, two years after that.

Mars Global Surveyor was the first of a sequence of 'faster, better, cheaper' NASA missions. This approach was subsequently renounced by the space agency, in large part because of the loss of the Surveyor's successors, Mars Climate Orbiter and Mars Polar Lander. But the idea of a continuous presence has persisted, with the various spacecraft calibrating and complementing each other's results, relaying each other's data when necessary, even taking pictures of each other. The fact that two spacecraft could help search for their fallen comrade is testament to the new age of exploration that the Surveyor inaugurated - even if, on this occasion, their efforts were in vain. 